\title{
Corrosion resistance of welded joints of X5CrNi18-10 stainless steel
}

\author{
Bore Jegdića $^{a}$, Biljana Bobića ${ }^{\text {, Bojana Radojkovića }}$, Behar Alić $c^{\mathrm{b}}$ Ljiljana Radovanovićc \\ ${ }^{a}$ University of Belgrade, Institute of Chemistry, Technology and Metallurgy, Njegoseva 12, Belgrade, Serbia \\ ${ }^{\mathrm{b}}$ Metallurgical Institute "Kemal Kapetanovic", Travnicka cesta 7, Zenica, Bosnia and Herzegovina \\ ' University of Novi Sad, Technical Faculty "Mihailo Pupin“, Zrenjanin, Serbia
}

\section{A R T I C L E I N F O}

Associate Editor: C.H. Caceres

Keywords:

Stainless steel

Welding

Nitrogen

Pitting corrosion

Intergranular corrosion

\begin{abstract}
A B S T R A C T
This paper considers the influence of nitrogen in the shielding gas during TIG welding as well as the influence of a welding current level on the resistance to pitting corrosion and intergranular corrosion in welded joints of X5CrNi18-10 stainless steel. Testing of pitting corrosion was carried out using the potentiodynamic method, while intergranular corrosion was tested with the Double-Loop Electrochemical Potentiokinetic Reactivation method. Pitting corrosion resistance of welded joints (the weld metal and the heat affected zone) is higher in the presence of nitrogen in the shielding gas, while integranular corrosion resistance remains unchanged. Pitting corrosion resistance of the heat affected zone in the welded joint formed in nitrogen-free shielding gas is lower than in the base metal, while the weld metal has similar pitting corrosion resistance as the base metal. With an increase in a welding current level, pitting corrosion resistance and resistance to intergranular corrosion of welded joints decrease. The passivation current density is shown to be a good indicator of pitting corrosion resistance of welded joints. Hardness values of the weld metal and the heat affected zone are slightly lower than the base metal hardness value.
\end{abstract}

\section{Introduction}

X5CrNi18-10 stainless steel (AISI 304) belongs to austenitic stainless steels with a wide range of applications in various industries. One of the disadvantages of these steels is the occurrence of pitting corrosion and intergranular corrosion in welded joints under operational conditions.

As Grubb (2011) noticed, during slow cooling of the mentioned stainless steel type in the temperature range from $820^{\circ} \mathrm{C}$ to $420^{\circ} \mathrm{C}$, carbides rich in chromium, primarily $\mathrm{M}_{23} \mathrm{C}_{6}$, precipitate on grain boundaries. Precipitation of carbides usually occurs in the heat affected zone (HAZ) due to slow diffusion of chromium in austenite (when compared to that of carbon), thus leading to grain boundary chromium depletion. Chromium depleted grain boundary regions have higher susceptibility to both intergranular and pitting corrosion.

The weld metal often shows low resistance to pitting corrosion due to its heterogeneous microstructure (the presence of the ferritic and austenitic phases). According to Davis (2006), pitting corrosion resistance of the weld metal can be improved by use of a filler metal containing a higher amount of chromium and nickel than the base metal.

Pits in austenitic stainless steels are usually formed around MnS inclusions. According to Ida et al. (2017), the formula of MnS inclusions is (Mn,Cr)S. Ke and Alkire (1995) observed that pitting corrosion resistance increases when the size of MnS inclusions decreases. Ryan et al. (2002) demonstrated that the chromium concentration decreases near MnS inclusions (at distances $<500 \mathrm{~nm}$ ) in relation to the chromium concentration in the austenitic matrix.

Seys et al. (1974) discovered that the $\mathrm{pH}$ value of the solution within the pit decreases due to the hydrolysis of metal ions while Galvele (1976) proposed the localized acidification model of pitting corrosion due to metal ions hydrolysis.

Before the formation of stable pits, metastable pits appear and become repassivated after a relatively short time. Tian et al. (2014) studied the appearance of metastable pitting by electrochemical methods and a 3D video microscope.

In accordance with ASTM F2129 standard (2015), the pitting potential, $E_{\text {pit }}$, or/and the pitting and corrosion potential difference, $E_{\mathrm{pit}}-E_{\text {corr }}$, are the indicators of pitting corrosion resistance. Tang et al. (2014) suggested that the metastable pitting potential $E_{\text {mpit }}$ and the difference $E_{\text {mpit }}-E_{\text {corr }}$ can also be the pitting corrosion resistance indicators.

It is known that nitrogen (especially in the presence of molybdenum) in stainless steels favourably influences the resistance to pit formation and pit growth. Osozawa et al. (1975) demonstrated that nitrogen in a pit is transformed into ammonia ions $\left(\mathrm{NH}_{4}{ }^{+}\right)$during pitting corrosion of stainless steels. The resulting $\mathrm{NH}_{4}{ }^{+}$ions prevent the

\footnotetext{
* Corresponding author.

E-mail address: bjegdic@tmf.bg.ac.rs (B. Jegdić).
} 
$\mathrm{pH}$ value decrease in the pit, which is necessary for the formation of stable pits:

$\mathrm{N}+4 \mathrm{H}^{+}+3 \mathrm{e}^{-} \rightarrow \mathrm{NH}_{4}^{+}$

In the presence of $\mathrm{NH}_{4}{ }^{+}$ions in the pit, a solution with a $\mathrm{pH}$ value higher than the critical $\mathrm{pH}$ value is formed. At $\mathrm{pH}$ values lower than the critical value, the formation and growth of stable pits occur. Therefore, the repassivation of a formed pit is easier in the early stage. However, in a sufficiently large pit, the corrosion environment is different due to the formation of a large amount of solvated $\mathrm{H}^{+}$ions which leads to a significant drop in the $\mathrm{pH}$ value. The formation of solvated $\mathrm{H}^{+}$ions causes chloride anions migration from the surrounding solution into the pit interior thus favouring conditions for the stable growth of large pits.

Jargelius-Pettersson (1999) showed that the nitrogen effect on pitting corrosion resistance can be also explained by nitrogen accumulation beneath the passive film. It was suggested that this nitrogen (beneath the passive film) was probably converted directly to ammonia ions.

Stainless steels with nitrogen and molybdenum are commercially produced because of their synergistic effect on the prevention of pitting corrosion. Bayoumi and Ghanem (2005) analysed the effect of nitrogen in stainless steels on pitting corrosion resistance. Raja et al. (1998) studied the influence of nitrogen amount on the microstructure and pitting corrosion behaviour of stainless steel overlay clad (904L) on mild steel. Zhang et al. (2017) examined the nitrogen influence on the microstructure of welded joints of duplex stainless steels and their resistance to localised corrosion. Lai et al. (2016) have recently studied the nitrogen influence on laser welded 2205 duplex stainless steel.

The resistance of stainless steels to pitting corrosion increases significantly in the presence of nitrogen. However, as shown by Lo et al. (2009), during welding, a nitrogen-chromium reaction can occur as well as the precipitation of $\mathrm{Cr}_{2} \mathrm{~N}$ at grain boundaries. This can also affect the susceptibility of stainless steels to intergranular corrosion.

The main aim of this paper is to examine the influence of nitrogen in the shielding gas on the pitting corrosion resistance and susceptibility to intergranular corrosion in welded joints of X5CrNi18-10 stainless steel. The influence of the welding current level was also studied.

\section{Experimental part}

\subsection{Material}

The welding of $\mathrm{X} 5 \mathrm{CrNi18-10}$ austenitic stainless steel was performed by tungsten inert gas (TIG) welding using the welding equipment with an automatic wire feeder (Fig. 1). Welding without a filler metal does not provide the required quality level of the welded joint.

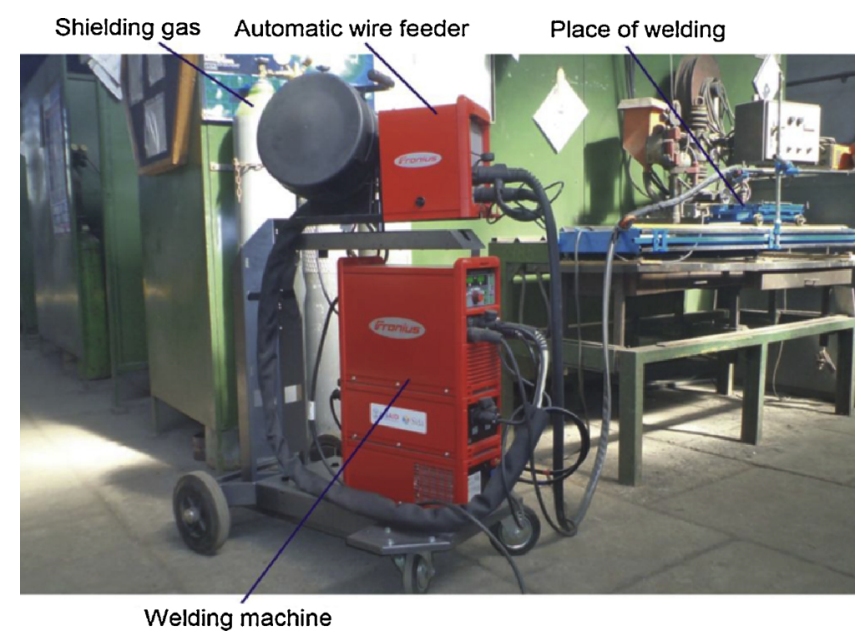

Fig. 1. Welding set-up.
Table 1

Chemical compositions of the base metal and the filler metal, mass.\%.

\begin{tabular}{llllllllll}
\hline Material & $\mathrm{C}$ & $\mathrm{Si}$ & $\mathrm{Mn}$ & $\mathrm{P}$ & $\mathrm{S}$ & $\mathrm{Cr}$ & $\mathrm{Ni}$ & $\mathrm{Mo}$ & $\mathrm{N}$ \\
\hline X5CrNi18-10 & 0.04 & 0.34 & 1.20 & 0.007 & 0.006 & 18.8 & 9.50 & 0.22 & 0.05 \\
MW 308 LSi $^{\mathrm{a}}$ & 0.03 & 0.80 & 1.90 & 0.007 & 0.007 & 20.1 & 9.90 & 0.07 & 0.06
\end{tabular}

a G 199 LSi according to EN 12072 standard (2000).

Table 2

Chemical compositions of the weld metal, mass.\% (I = $150 \mathrm{~A})$.

\begin{tabular}{llllllll}
\hline Material & $\mathrm{C}$ & $\mathrm{Si}$ & $\mathrm{Mn}$ & $\mathrm{Cr}$ & $\mathrm{Ni}$ & $\mathrm{Mo}$ & $\mathrm{N}$ \\
\hline $\mathrm{WM}(\mathrm{Ar})$ & 0.044 & 0.53 & 1.44 & 18.30 & 8.40 & 0.18 & 0.084 \\
$\mathrm{WM}(\mathrm{Ar}+1.25$ vol.\% N ) & 0.044 & 0.46 & 1.43 & 18.50 & 8.50 & 0.18 & 0.130 \\
$\mathrm{WM}\left(\mathrm{Ar}+2.50\right.$ vol.\% N $\left.\mathrm{N}_{2}\right)$ & 0.069 & 0.56 & 1.40 & 18.20 & 8.10 & 0.18 & 0.170 \\
\hline
\end{tabular}

After welding, the welded joints were examined using non-destructive test methods. For further testing, welded joints of high quality were selected in accordance with ISO 5817 standard (2003).

Argon without nitrogen was used as a shielding gas as well as argon with 1.25 vol. $\%$ nitrogen and 2.50 vol. $\%$ nitrogen. The welding current was $150 \mathrm{~A}$.

The chemical compositions of the X5CrNi18-10 stainless steel and the filler metal (MW 308LSi) were determined by the spectrophotometric method and are shown in Table 1. The chemical compositions of the weld metal (WM) formed in the shielding gas with different content of nitrogen are given in Table 2.

After welding, the nitrogen content in the weld metal was determined in accordance with ISO 10702 standard (2001).

The amount of $\delta$-ferrite in the weld metal was determined by use of a FERITSCOPE MP30E. The $\delta$-ferrite content, expressed in terms of percentages, is the ferrite number.

The hardness was measured with a ZWICK device. The measurements were performed in the weld metal, in the heat affected zone and in the base metal. The hardness measurement results (given in Table 3) show that the weld metal hardness values and the HAZ hardness values are slightly lower than the hardness values of the base metal. The lowest hardness values were measured in the heat affected zone.

\subsection{Methods}

\subsubsection{Pitting corrosion testing}

The pitting corrosion testing was performed using the potentiodynamic method with a potentiostat/galvanostat BIOLOGIC SP 200. The tests were carried out on the base metal, in the weld metal, and in the heat affected zone. Prior to the testing, the samples were abraded with progressively finer SiC paper and then degreased in ethanol.

The tests were performed in a three-electrode electrochemical cell with a saturated calomel electrode as a reference electrode (SCE) and a platinum mesh as a counter electrode. A special electrochemical cell for direct testing in the weld metal, the heat affected zone, and the base metal was designed. Since this cell was applied for electrochemical testing, it was not necessary to cut separate specimens from the welded joints. The tested sample surface was $0.785 \mathrm{~cm}^{2}$. The tests were performed at room temperature in $0.3 \mathrm{~mol} \mathrm{dm}^{-3} \mathrm{NaCl}+0.1 \mathrm{~mol} \mathrm{dm}^{-3}$ $\mathrm{Na}_{2} \mathrm{SO}_{4}$. When a stable $E_{\text {corr }}$ value was established, the anodic curves were recorded (with a $0.5 \mathrm{mV} \mathrm{s}^{-1}$ scan rate). The $E_{\text {pit }}$ and $E_{\text {mpit }}$ values were determined from the recorded polarisation curves.

ISO 15158 standard (2014) defines $E_{\text {pit }}$ as a potential when the anodic current density $j_{\mathrm{a}}<10 \mu \mathrm{Acm}^{-2}$ in the region of a stable pit growth. In this paper, $E_{\text {mpit }}$ is defined as a potential when the anodic current density $j_{\mathrm{a}}<0.02 \mu \mathrm{Acm}^{-2}$ (in the passive area), as demonstrated by Tang et al. (2014). 
Table 3

Hardness of the weld metal, the heat affected zone and the base metal.

\begin{tabular}{|c|c|c|c|c|c|c|c|c|c|c|c|c|c|}
\hline \multirow{3}{*}{$\begin{array}{l}\text { Shielding gas } \\
\\
\mathrm{Ar}\end{array}$} & \multicolumn{13}{|c|}{ HV10 } \\
\hline & \multicolumn{2}{|c|}{ Base metal (left) } & \multicolumn{3}{|c|}{ HAZ (left) } & \multicolumn{3}{|c|}{ Weld metal } & \multicolumn{3}{|c|}{$\begin{array}{l}\text { HAZ } \\
\text { (right) }\end{array}$} & \multicolumn{2}{|c|}{ Base metal (right) } \\
\hline & 198 & 198 & 196 & 172 & 171 & 186 & 191 & 191 & 180 & 186 & 201 & 206 & 206 \\
\hline $\mathrm{Ar}+1.25$ vol. $\% \mathrm{~N}_{2}$ & 206 & 206 & 196 & 198 & 181 & 181 & 181 & 181 & 177 & 181 & 203 & 206 & 206 \\
\hline $\mathrm{Ar}+2.50 \mathrm{vol} . \% \mathrm{~N}_{2}$ & 206 & 201 & 191 & 186 & 171 & 164 & 168 & 168 & 173 & 181 & 196 & 201 & 201 \\
\hline
\end{tabular}

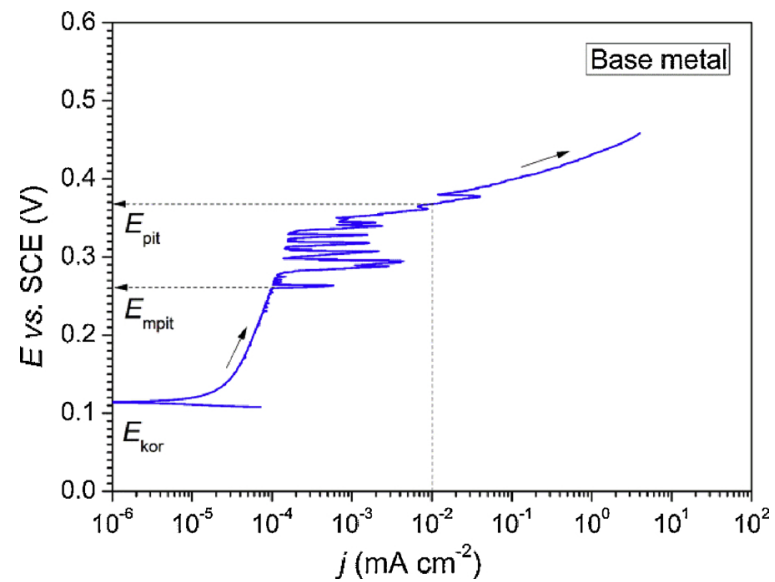

Fig. 2. Polarisation curve for the base metal.
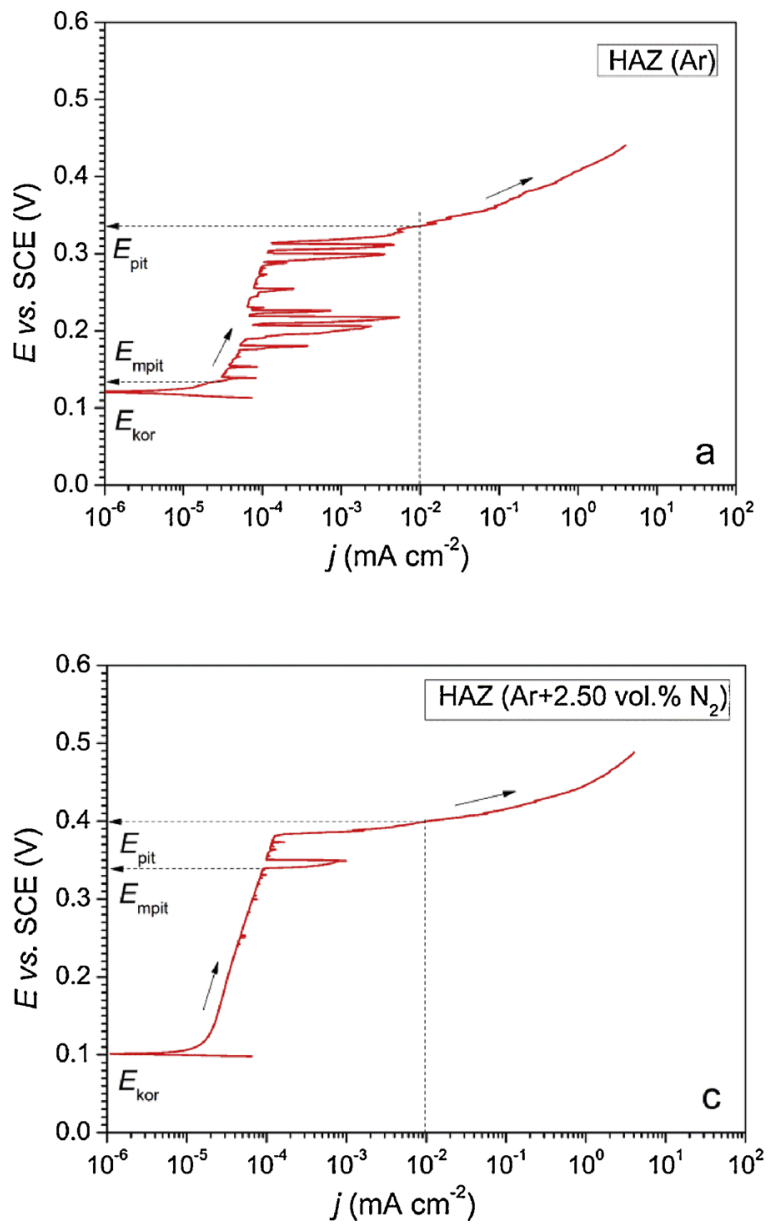

\subsubsection{Intergranular corrosion testing}

The intergranular corrosion was tested by the Double Loop Electrochemical Potentiokinetic Reactivation method (DL EPR method). The test was performed on the base metal and in the heat affected zone. The same electrochemical cell was used for pitting corrosion testing. In accordance with ISO 15158 standard (2014), the test was carried out in the following solution: $0.5 \mathrm{~mol} \mathrm{dm}^{-3}$ $\mathrm{H}_{2} \mathrm{SO}_{4}+0.01 \mathrm{~mol} \mathrm{dm}{ }^{-3} \mathrm{KSCN}$. The sample potential was shifted from $E_{\text {corr }}$ in the positive direction to passivation $(+300 \mathrm{mV})$ at a $1.67 \mathrm{mV} \mathrm{s}^{-1}$ scan rate. Immediately after the passivation potential $(+300 \mathrm{mV})$ had been reached, the potential of the sample was returned to $E_{\text {corr }}$.

If a stainless steel type is susceptible to intergranular corrosion, grain boundaries are activated in the reverse part of the loop (reactivation). The ratio of the amount of charge spent during reactivation (i.e. when dissolving the grain boundaries, $Q_{r}$ ) and the amount of charge spent during activation (i.e. when dissolving the grains and the grain boundaries, $Q_{p}$ ) is a measure of the intergranular corrosion susceptibility, $\left(Q_{\mathrm{r}} / Q_{\mathrm{p}}\right)_{\mathrm{GBA}}$ :

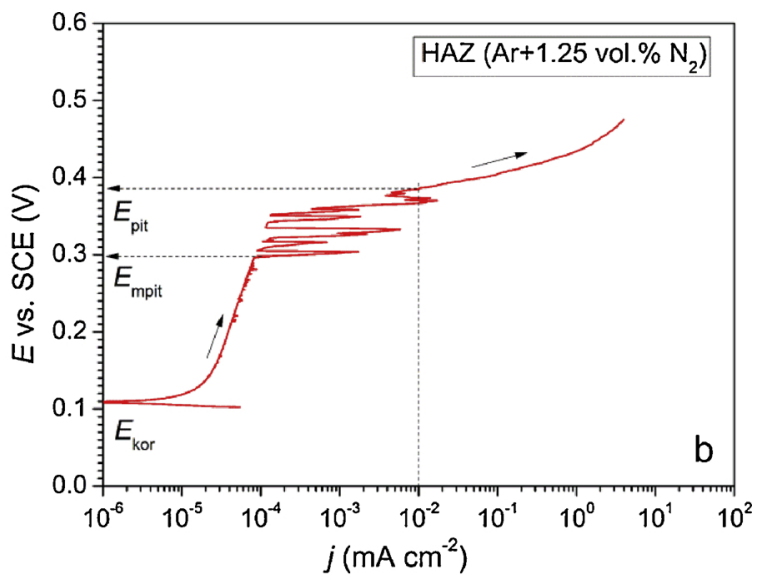

Fig. 3. Polarisation curves for the heat affected zone formed: a) without $\mathrm{N}_{2}$, b) with 1.25 vol. $\% \mathrm{~N}_{2}$, and c) with 2.50 vol.\% $\mathrm{N}_{2}$ in the shielding gas. 

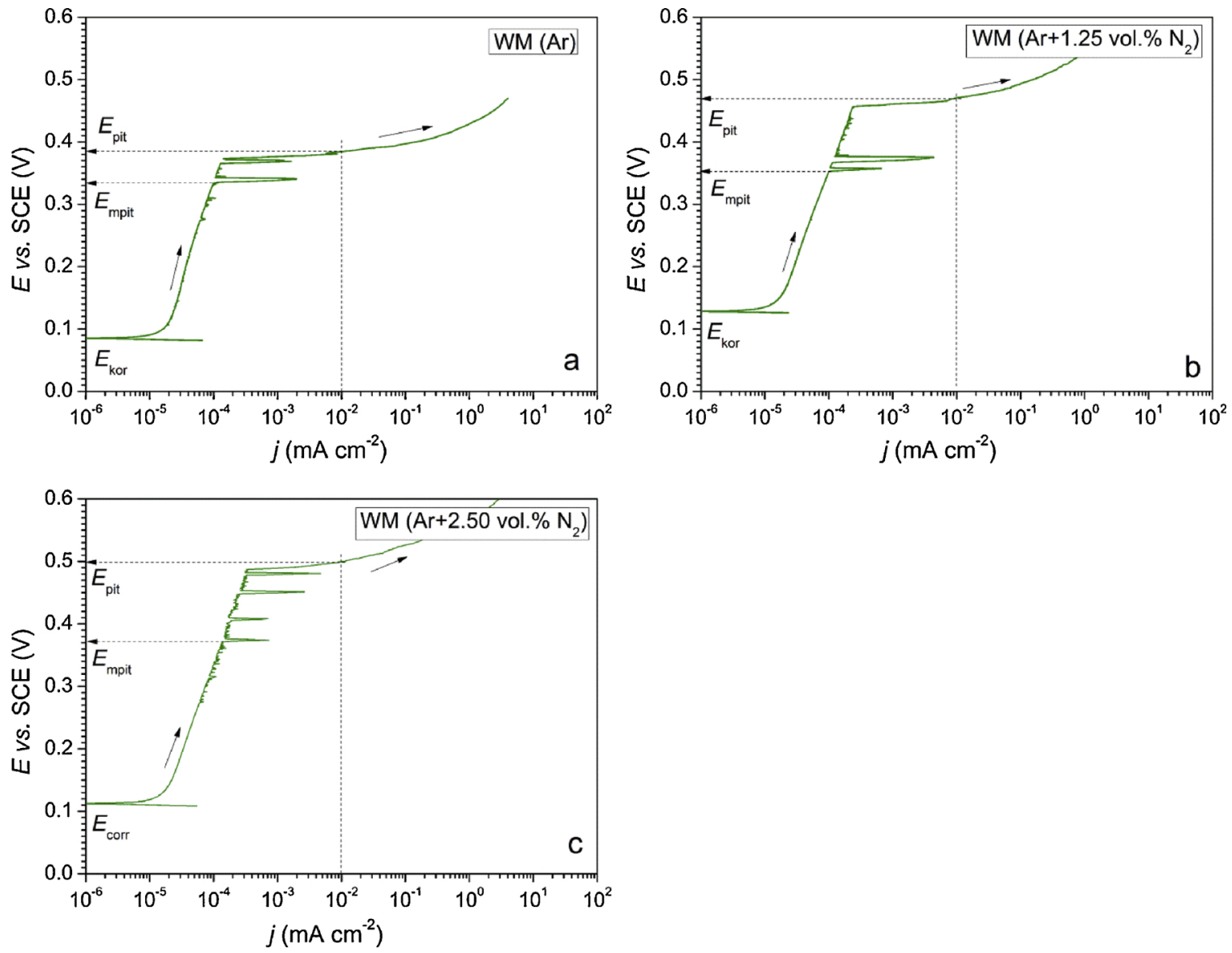

Fig. 4. Polarisation curves for the weld metal formed: a) without $\mathrm{N}_{2}$, b) with $1.25 \mathrm{vol} . \% \mathrm{~N}_{2}$, and c) with 2.50 vol. $\% \mathrm{~N}_{2}$ in the shielding gas.

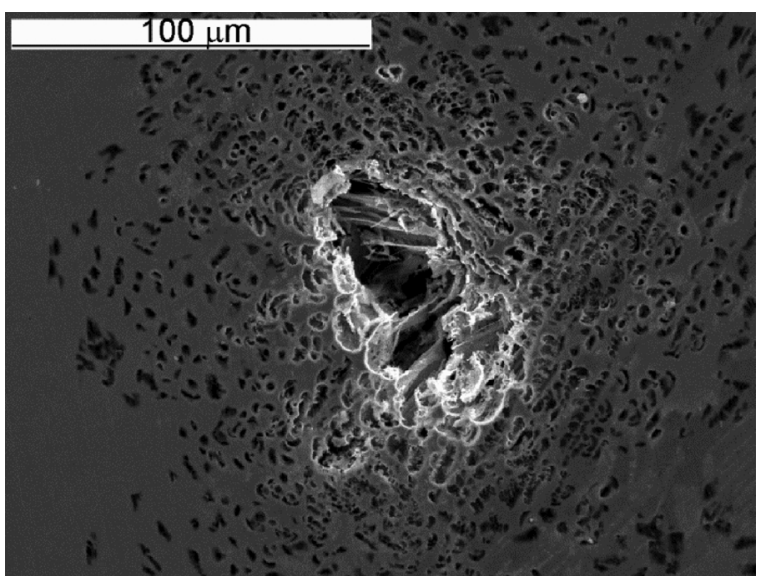

Fig. 5. SEM/SEI micrograph of a pit formed during the pitting corrosion test.

$\left(\frac{\mathrm{Q}_{\mathrm{r}}}{\mathrm{Q}_{\mathrm{p}}}\right)_{\mathrm{GBA}}=\frac{\mathrm{Q}_{\mathrm{r}}}{\mathrm{Q}_{\mathrm{p}} \cdot\left(10^{-3} \cdot \sqrt{2^{\mathrm{G}+5}}\right)}$

where $\mathrm{G}$ is the grain size, in accordance with ISO 643 standard (2003).

In accordance with ASTM G108 standard (2015), the width of the sensitised zone depleted in chromium on each side of the grain boundaries is $\sim 500 \mathrm{~nm}$. The total area of the sensitised zones along the boundaries of all grains on the sample surface $S_{\mathrm{GBA}}$ can be calculated using the following expression, in accordance with ISO 12732 standard (2006):

$\mathrm{S}_{\mathrm{GBA}}=\mathrm{A}_{\mathrm{S}} \cdot\left(10^{-3} \cdot \sqrt{2^{\mathrm{G}+5}}\right)$,

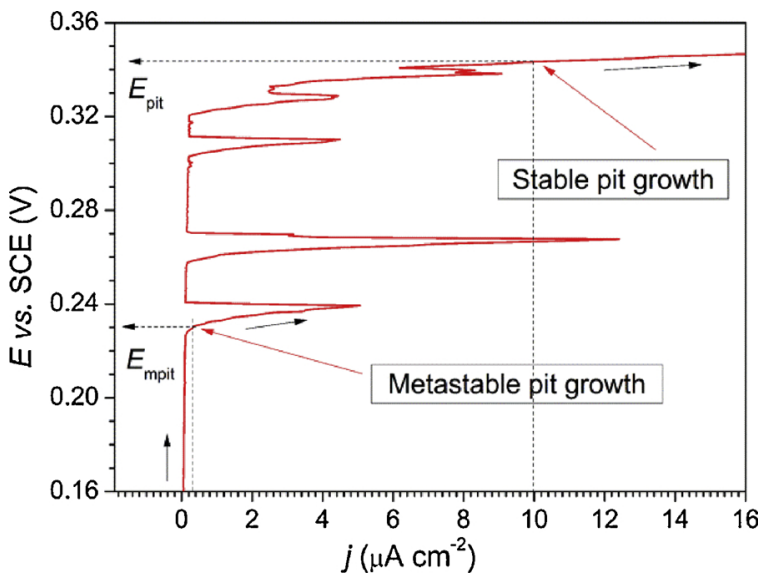

Fig. 6. Formation and growth of metastable and stable pits.

where $A_{\mathrm{s}}$ is the sample surface.

As stated in ISO 12732 standard (2006), if the value of the indicator $Q_{\mathrm{r}} / Q_{\mathrm{p}}>5 \%$, it can be expected that intergranular corrosion of stainless steels occurs under real service conditions.

\subsubsection{SEM/EDS analysis}

A scanning electron microscope SEM JEOL JSM-6610LV, which operates at $20 \mathrm{kV}$, equipped for energy dispersive spectroscopy (EDS) measurements, was applied for the analysis of the stainless steel surface morphology after the pitting corrosion and intergranular corrosion testing. The same scanning electron microscope was used for the microstructural analysis as well as for the analysis of the chemical 
Table 4

Results of the pitting corrosion tests.

\begin{tabular}{|c|c|c|c|c|c|}
\hline Material & $E_{\text {corr }}(\mathrm{mV})$ & $j_{\text {pass }(+200 \mathrm{mV})}\left(\mathrm{nA} \mathrm{cm}^{-2}\right)$ & $E_{\text {mpit }}(\mathrm{mV})$ & $E_{\text {pit }}(\mathrm{mV})$ & $E_{\text {pit }}-E_{\text {corr }}(\mathrm{mV})$ \\
\hline Base metal & 100 & 50 & 330 & 385 & 285 \\
\hline HAZ (Ar) & 120 & 72 & 195 & 335 & 215 \\
\hline $\mathrm{HAZ}\left(\mathrm{Ar}+1.25\right.$ vol. $\left.\% \mathrm{~N}_{2}\right)$ & 110 & 38 & 325 & 370 & 260 \\
\hline $\mathrm{HAZ}\left(\mathrm{Ar}+2.50\right.$ vol. $\left.\% \mathrm{~N}_{2}\right)$ & 100 & 32 & 340 & 400 & 300 \\
\hline WM (Ar) & 85 & 38 & 335 & 385 & 300 \\
\hline $\mathrm{WM}\left(\mathrm{Ar}+1.25\right.$ vol. $\left.\% \mathrm{~N}_{2}\right)$ & 130 & 30 & 370 & 470 & 340 \\
\hline $\mathrm{WM}\left(\mathrm{Ar}+2.50\right.$ vol. $\left.\% \mathrm{~N}_{2}\right)$ & 115 & 30 & 375 & 500 & 385 \\
\hline
\end{tabular}

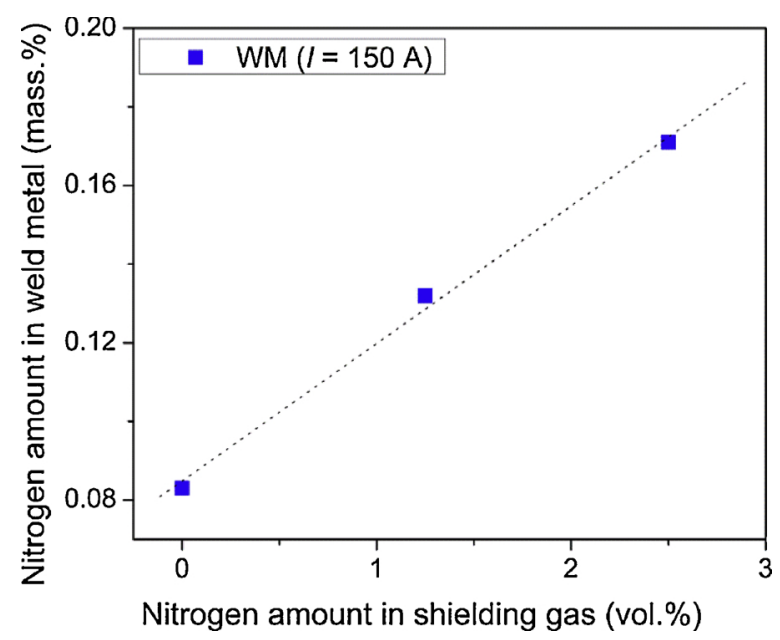

Fig. 7. Dependence of the nitrogen amount in the weld metal on the nitrogen amount in the shielding gas.

composition of the austenitic and ferritic phases in the weld metal.

The grain size G, required to calculate the degree of stainless steel sensitisation to intergranular corrosion (Eq. (2)), was determined by the scanning electron microscope. The grain size was measured in the heat affected zone as well as on the base metal and, in all cases, it was from $18 \mu \mathrm{m}$ to $20 \mu \mathrm{m}$ ( G9), in accordance with ISO 643 (2003) standard.

\section{Results and discussion}

\subsection{Pitting corrosion resistance}

The results of the pitting corrosion tests are shown in Figs. 2-5. Fig. 2 presents the polarisation curve recorded on the base metal. Fig. 3a-c give the polarisation curves for the heat affected zone (HAZ) formed in the nitrogen-free shielding gas (argon) and in the shielding gas with nitrogen. Fig. 4a-c show the polarisation curves for the weld metal (WM) obtained with and without nitrogen in the shielding gas. The values of the pitting corrosion parameters, i.e. the values of $E_{\text {corr }}$, $E_{\text {mpit }}$ and $E_{\text {pit }}$, are indicated in the Figures.

A SEM micrograph of a characteristic pit formed on the stainless steel surface during the electrochemical test is shown in Fig. 5.

Relatively small current peaks, noticeable on the polarisation curve (Fig. 6), indicate the appearance of metastable pits on the stainless steel surface. The appearance of metastable pits is manifested by a gradual increase in the current to a certain value, followed by a sudden decrease in the current (Fig. 6). The decreasing current indicates the repassivation of metastable pits. This type of metastable pitting is characteristic for austenitic stainless steels. In this work, the potential at which the anodic current density is higher than $0.02 \mu \mathrm{A} \mathrm{cm}^{-2}$ in relation to the passivation current density $j_{\text {pass }}$ is taken as the potential of metastable pit formation $E_{\text {mpit }}$ in accordance with Tang et al. (2014). A further increase in potential leads to meeting the conditions for the appearance of stable pits on the stainless steel surface. During the growth of stable pits, the current density rapidly increases and then continues to grow.

Table 4 shows the values of the pitting corrosion indicators $\left(E_{\text {mpit }}\right.$, $E_{\mathrm{pit}}$ and $\left.E_{\mathrm{pit}}-E_{\text {corr }}\right)$ and the values of the passivation current density $j_{\text {pass }(+200 \mathrm{mV})}$ for the base metal, the heat affected zone (HAZ), and the weld metal (WM), obtained from the recorded polarisation curves.

The values of $E_{\text {corr }}$ established on the samples before the test are relatively close. The nature of the $E_{\text {corr }}$ formed on AISI 304 stainless steel in chloride and sulphate solutions was discussed in detail by Jegdić et al. (2008).

\subsubsection{Welded joint formed in the shielding gas without nitrogen}

The values of $E_{\text {mpit }}, E_{\mathrm{pit}}$, and $E_{\mathrm{pit}}-E_{\text {corr }}$ for the heat affected zone are lower than the corresponding values for the base metal. The precipitation of chromium carbides occurred at the grain boundaries in the heat affected zone, which resulted in the sensitisation of the grain boundary areas. This caused lower pitting corrosion resistance of the
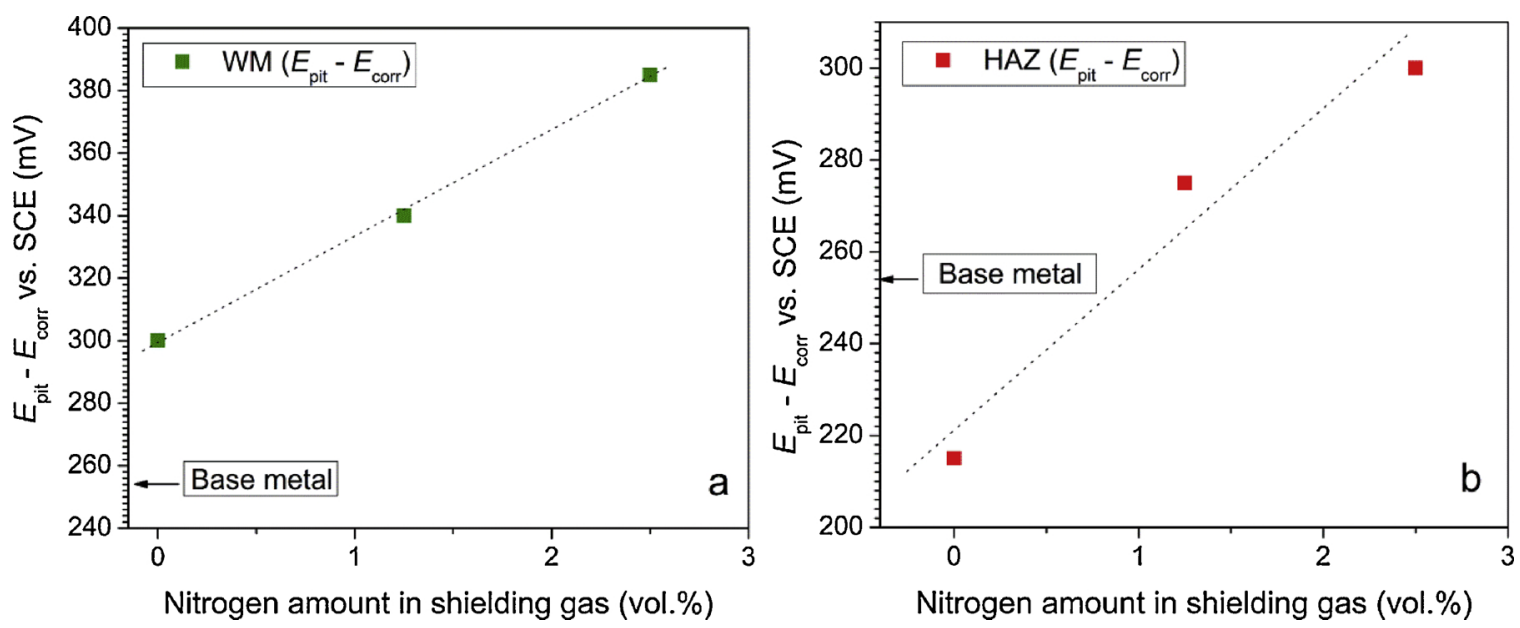

Fig. 8. Dependence of pitting corrosion resistance on the nitrogen amount: a) weld metal and b) heat affected zone. 

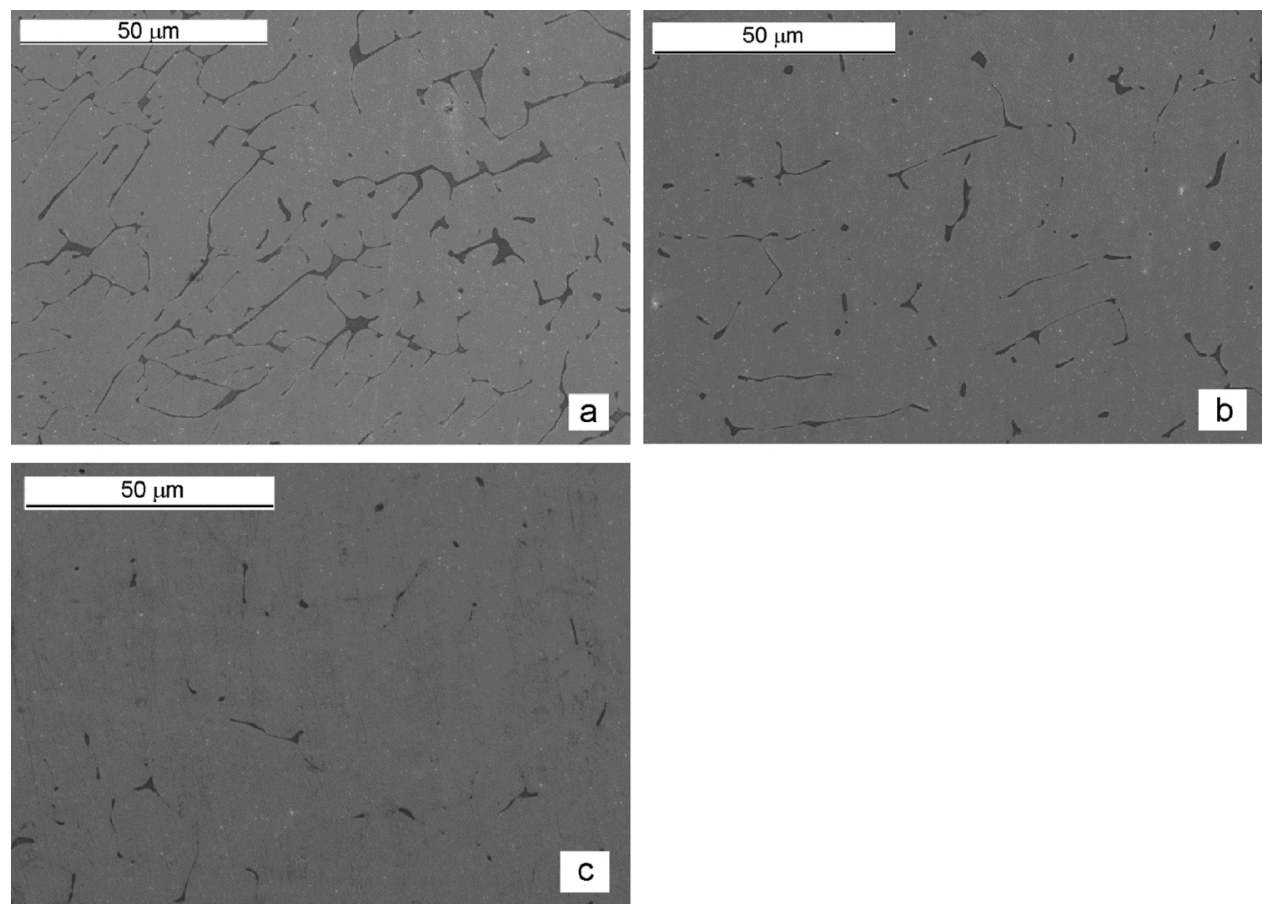

Fig. 9. SEM/SEI micrographs of the weld metal formed: a) without $\mathrm{N}_{2}$, b) with 1.25 vol. $\% \mathrm{~N}_{2}$ and c) with 2.50 vol. $\% \mathrm{~N}_{2}$ in the shielding gas.
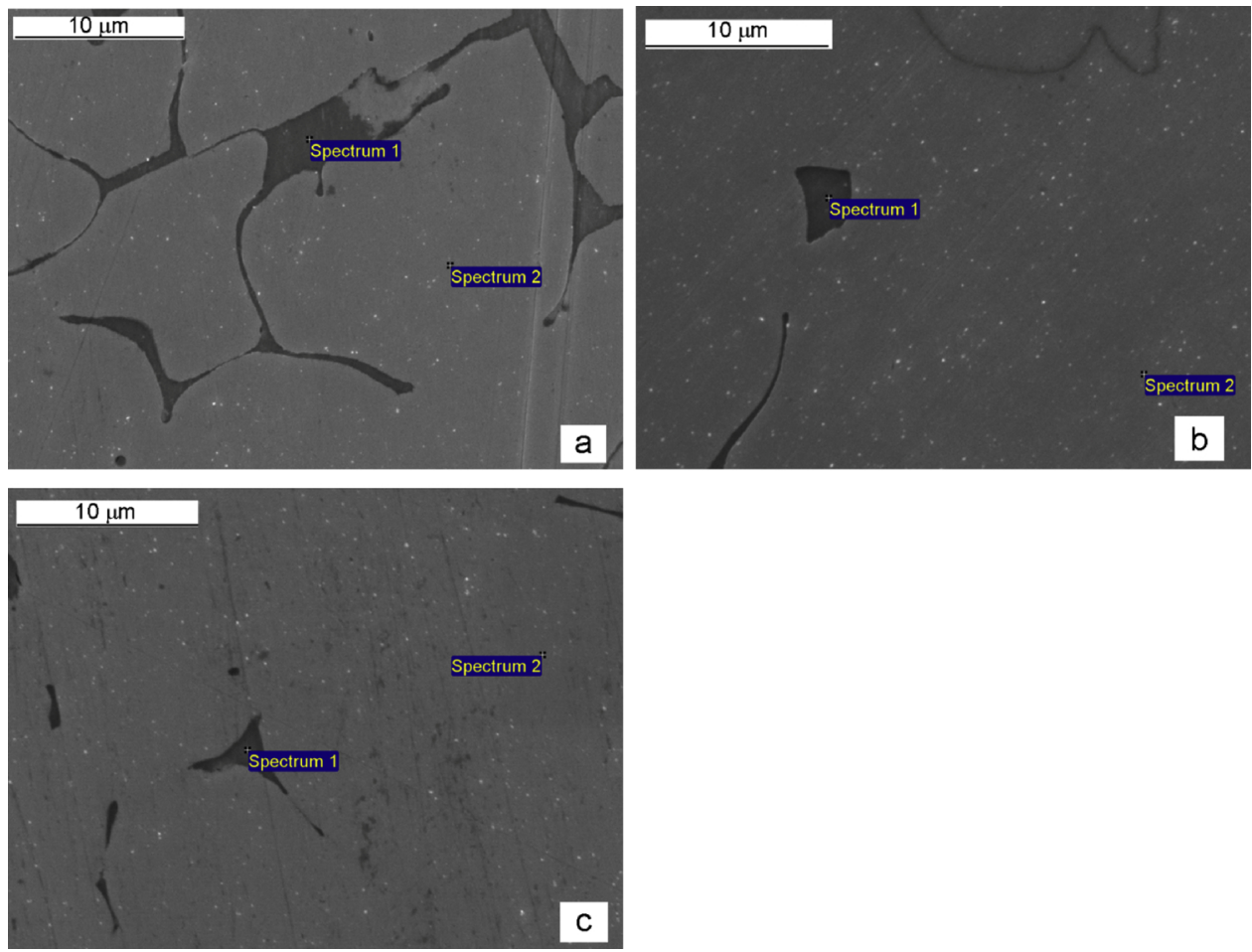

Fig. 10. Positions of the SEM/EDS measurements in the ferritic phase (spectrum 1) and the austenitic phase (spectrum 2) for the weld metal formed: a) without $\mathrm{N}_{2}$, b) with 1.25 vol. $\% \mathrm{~N}_{2}$ and c) with 2.50 vol. $\% \mathrm{~N}_{2}$ in the shielding gas.

heat affected zone. The kinetics of the formation of chromium carbides at grain boundaries of similar austenitic stainless steels (subjected to different heat treatment regimes that correspond to different welding conditions) has recently been analysed by Kaneko et al. (2011) with sophisticated microscopic techniques. Yanliang et al. (2008) applied atomic force microscopy to study sensitisation to stress corrosion cracking of austenitic stainless steels.

Ryan et al. (2002) consider that pits in stainless steels are formed at the boundary of the austenitic matrix and $\mathrm{MnS}$ inclusions. In this region (with a size below $500 \mathrm{~nm}$ ), depletion in chromium occurs. It was shown that the $\mathrm{Cr} / \mathrm{Fe}$ ratio was lower in this region than in the austenitic matrix; therefore, the formation of pits was easier. On the other hand, Ida et al. (2017) have recently demonstrated that the co-existence of MnS inclusions and the chromium-depleted zones at grain boundaries is a critical factor in the pit initiation of sensitised AISI 304 stainless steels. 
Table 5

Chemical compositions of the ferritic and austenitic phases, mass.\% (Fig. 10).

\begin{tabular}{lllllll}
\hline Material & Spectrum & $\mathrm{Cr}$ & $\mathrm{Ni}$ & $\mathrm{Fe}$ & $\mathrm{Mn}$ & $\mathrm{Si}$ \\
\hline \multirow{2}{*}{ WM (Ar) } & Spectrum 1 & 25.46 & 4.30 & 68.70 & 1.43 & 0.64 \\
& Spectrum 2 & 18.82 & 9.43 & 69.75 & 1.36 & 0.64 \\
WM (Ar + 1.25 vol.\% N 2 ) & Spectrum 1 & 25.83 & 4.31 & 67.70 & 1.42 & 0.73 \\
& Spectrum 2 & 19.11 & 9.42 & 69.39 & 1.50 & 0.58 \\
WM (Ar + 2.50 vol.\% N 2 ) & Spectrum 1 & 25.02 & 3.55 & 69.41 & 1.23 & 0.78 \\
& Spectrum 2 & 19.33 & 8.89 & 69.75 & 1.40 & 0.63
\end{tabular}

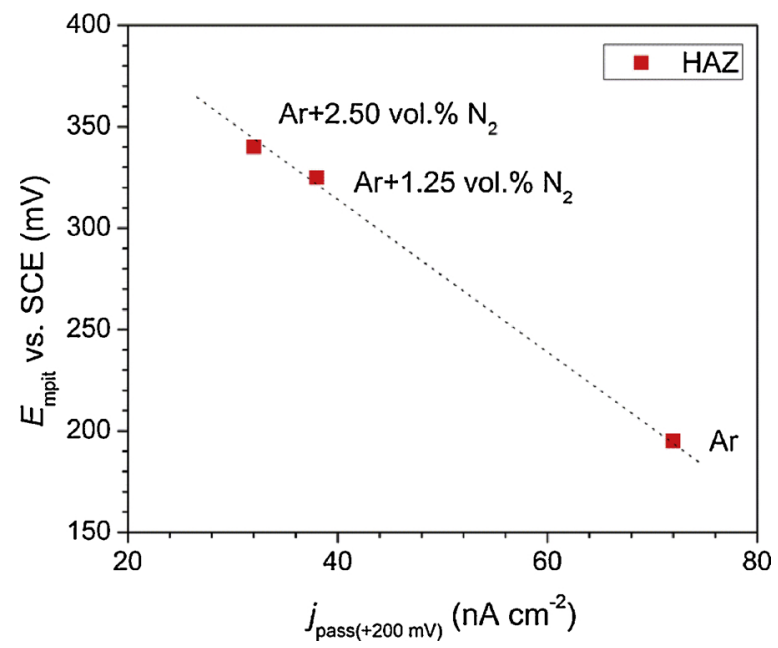

Fig. 11. Dependence between the potential of metastable pit formation and the passivation current density.

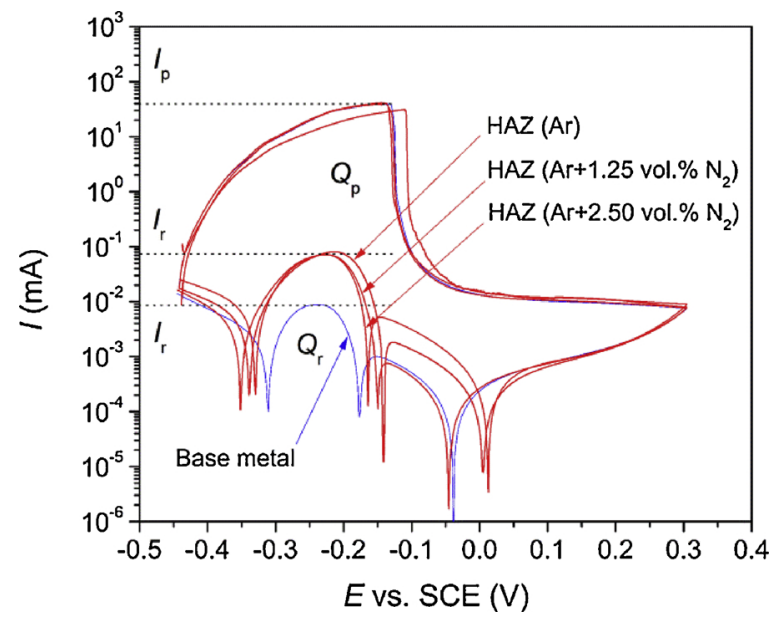

Fig. 12. Results of the intergranular corrosion tests.

The values of $E_{\text {pit }}$ and $E_{\text {mpit }}$ for the weld metal and the base metal are very similar. The weld metal microstructure is heterogeneous and consists of austenitic and ferritic phases (the ferrite content in the weld metal is $\sim 10 \%)$. Pits are easily formed at the ferritic/austenitic interface. In addition, the chromium content in the austenitic phase was reduced during the weld metal solidification due to the precipitation of the ferritic phase (the phase rich in chromium). However, the weld metal shows a slightly greater pitting corrosion resistance compared to the base metal. The $E_{\text {pit }}-E_{\text {corr }}$ difference for the weld metal is bigger than the corresponding difference for the base metal.

\subsubsection{Welded joint formed in the shielding gas with nitrogen}

Table 4 also shows the experimentally obtained values of the pitting corrosion indicators for the welded joint formed in the presence of

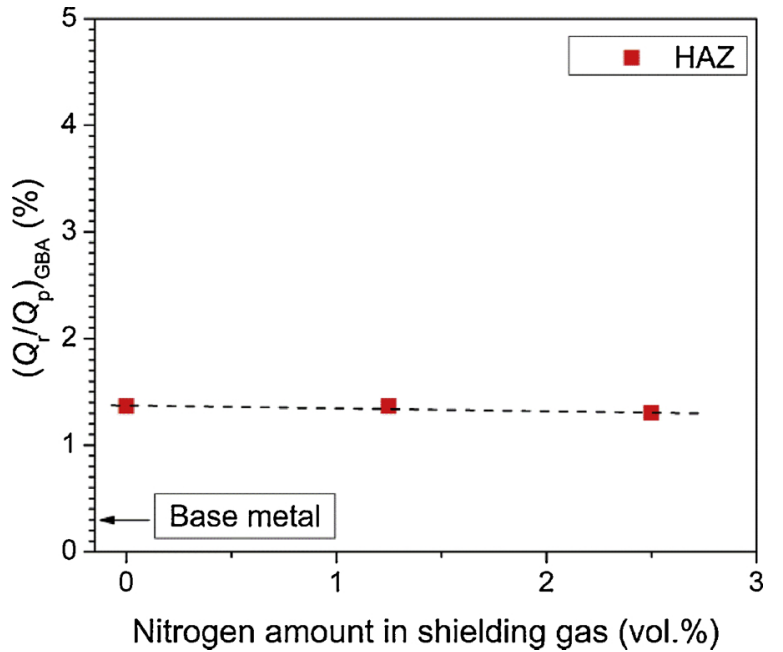

Fig. 13. $\left(\mathrm{Q}_{\mathrm{r}} / \mathrm{Q}_{\mathrm{p}}\right)_{\mathrm{GBA}}$ dependence on the nitrogen amount in the shielding gas.

nitrogen. During welding, nitrogen from the shielding gas was dissociated at high temperatures of the electric arc and partly dissolved in the weld metal. Fig. 7 shows the dependence of the nitrogen amount in the weld metal (WM) on the nitrogen amount in the shielding gas. This dependence is approximately linear.

As it can be seen in Figs. 3 and 4, as well as in Table 4, the values of $E_{\mathrm{pit}} E_{\mathrm{mpit}}$ and $E_{\mathrm{pit}}-E_{\text {corr }}$ in the weld metal are higher in the presence of nitrogen in the shielding gas than in its absence. These values are also higher for the heat affected zone in the presence of nitrogen. Higher values of the HAZ pitting corrosion indicators are caused by easier nitrogen diffusion from the weld metal to the heat affected zone at elevated temperatures during the welded joint solidification.

Fig. 8 shows the dependence of the $E_{\text {pit }}-E_{\text {corr }}$ value on the amount of nitrogen in the shielding gas for the weld metal (WM) and for the heat affected zone (HAZ). A similar dependence was observed for the metastable pitting potential, $E_{\text {mpit }}$ (Table 4 ).

The values of $E_{\mathrm{pit}}, E_{\mathrm{mpit}}$, and $E_{\mathrm{pit}}-E_{\mathrm{corr}}$ (Table 4) indicate the significant influence of nitrogen on the pit formation in the welded joint. It can be expected that the nitrogen influence is more significant at a higher content of molybdenum in stainless steels due to the synergetic effect of molybdenum and nitrogen, as shown by Kim (2010).

The values of $E_{\text {pit }}, E_{\text {mpit }}$, and $E_{\text {pit }}-E_{\text {corr }}$ are higher for the weld metal containing nitrogen than for the weld metal without nitrogen. This can be explained by an increased $\mathrm{pH}$ value of the solution in the pits due to the formation of $\mathrm{NH}_{4}{ }^{+}$ions in the presence of nitrogen (Eq. (1)). In addition, in the presence of nitrogen, the $\delta$-ferrite fraction in the weld metal is reduced (Fig. 9), which has a favourable effect on the weld metal resistance to pitting corrosion.

During welding in the nitrogen-free shielding gas, the $\delta$-ferrite content in the weld metal is $\sim 10 \%$. During welding in the shielding gas with 1.25 vol. $\% \mathrm{~N}_{2}$, the content of $\delta$-ferrite decreases to $\sim 3-4 \%$, while in the case of the shielding gas with $2.50 \mathrm{vol} . \% \mathrm{~N}_{2}$, the content of $\delta$ ferrite decreases to $\sim 2-3 \%$. The chromium content in $\delta$-ferrite is higher than the average chromium content in the weld metal. The nitrogen presence led to a decrease in the fraction of $\delta$-ferrite (the phase rich in chromium), and to a higher austenitisation of the weld metal. As a result, there was an increase in the chromium content in the austenitic phase. The concentrations of chromium and other alloying elements were determined by the SEM/EDS analysis in the ferritic phase (dark fields in Fig. 10), as well as in the austenitic phase (bright fields in Fig. 10). The results obtained for the weld metal (WM) are shown in Table 5.

Pit formation is easier at the ferritic/austenitic phase boundary. However, in the presence of nitrogen, the microstructure of the weld metal was homogenised. Therefore, the surface of the ferritic/austenitic 
Table 6

Results of the intergranular corrosion tests.

\begin{tabular}{|c|c|c|c|c|c|c|}
\hline Material & $E_{\text {corr }}(\mathrm{mV})$ & $I_{\mathrm{p}}(\mu \mathrm{A})$ & $I_{\mathrm{r}}(\mu \mathrm{A})$ & $Q_{\mathrm{p}}(\mathrm{mC})$ & $Q_{\mathrm{r}}(\mathrm{mC})$ & $\left(Q_{\mathrm{r}} / Q_{\mathrm{p}}\right)_{\mathrm{GBA}}(\%)$ \\
\hline Base metal & -442 & 38,961 & 8.7 & 2954 & 0.728 & 0.229 \\
\hline HAZ (Ar) & -436 & 35,839 & 80.7 & 3364 & 4.940 & 1.364 \\
\hline HAZ $\left(\mathrm{Ar}+1.25\right.$ vol. $\left.\% \mathrm{~N}_{2}\right)$ & -442 & 40,961 & 71.9 & 3052 & 4.479 & 1.364 \\
\hline $\mathrm{HAZ}\left(\mathrm{Ar}+2.50\right.$ vol. $\left.\% \mathrm{~N}_{2}\right)$ & -440 & 38,765 & 71.8 & 2930 & 4.113 & 1.304 \\
\hline
\end{tabular}
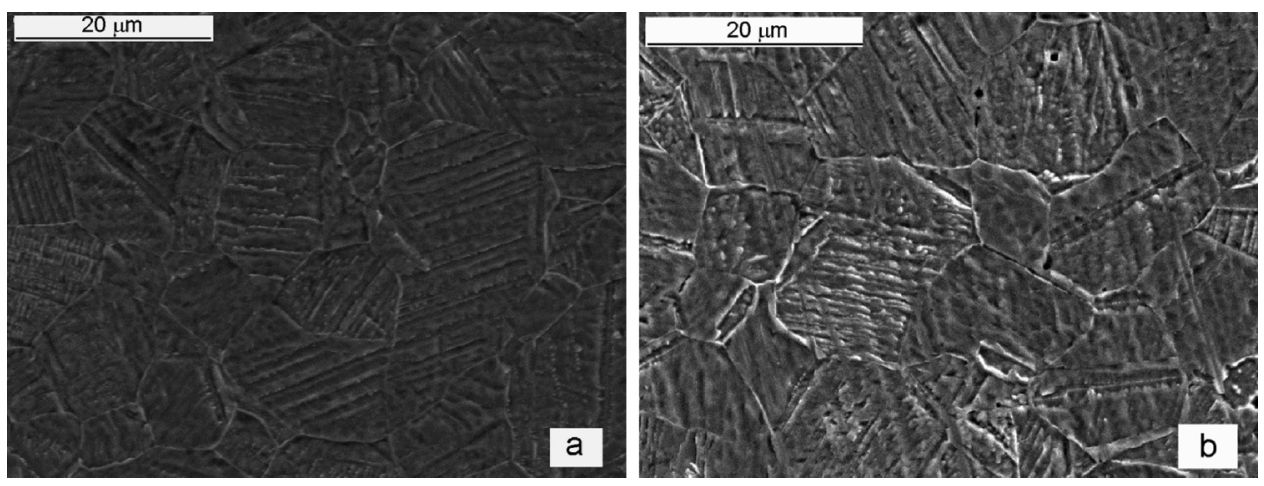

Fig. 14. SEM/SEI micrographs of the stainless steel surface after the intergranular corrosion test: a) the base metal and b) the heat affected zone.

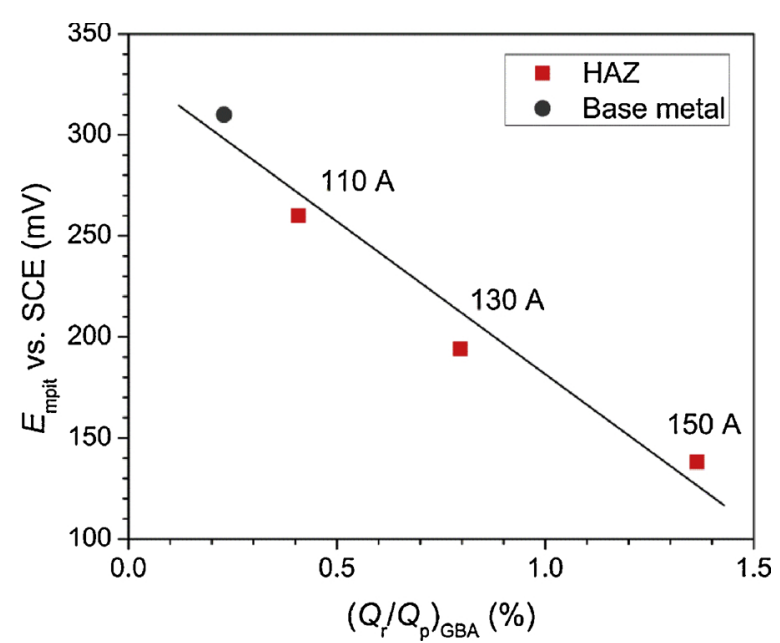

Fig. 15. Influence of a welding current level on pitting corrosion resistance and intergranular corrosion resistance.

Table 7

Indicators of resistance to pitting and intergranular corrosion in the heat affected zone.

\begin{tabular}{lllll}
\hline $\begin{array}{l}\text { Welding current, } I \\
(\mathrm{~A})\end{array}$ & $\begin{array}{l}E_{\mathrm{mpit}} \\
(\mathrm{mV})\end{array}$ & $E_{\mathrm{pit}}(\mathrm{mV})$ & $E_{\mathrm{pit}}-E_{\mathrm{corr}}(\mathrm{mV})$ & $\begin{array}{l}\left(Q_{\mathrm{r}} / Q_{\mathrm{p}}\right)_{\mathrm{GBA}} \\
(\%)\end{array}$ \\
\hline 110 & 260 & 364 & 286 & 0.408 \\
130 & 194 & 368 & 253 & 0.797 \\
150 & 138 & 335 & 215 & 1.364 \\
\hline
\end{tabular}

phase boundary was reduced (Fig. 10). This led to the increase of pitting corrosion resistance in the weld metal.

The observed increase of pitting corrosion resistance in the weld metal with nitrogen was significant even though the weld metal did not contain molybdenum, so there was not a synergetic effect of nitrogen and molybdenum.

3.1.3. Passivation current density and pitting corrosion resistance of the welded joint

The values of the passivation current density at a potential of
$+200 \mathrm{mV}, j_{\text {pass }(+200 \mathrm{mV})}$ are in relatively good accordance with the values of the pitting corrosion indicators (Table 4). The highest value of $j_{\text {pass }(+200 \mathrm{mV})}=72 \mathrm{nA} \mathrm{cm}^{-2}$ was obtained in the heat affected zone formed without nitrogen in the shielding gas. In this case, the lowest values for $E_{\text {mpit }}, E_{\text {pit }}$, and $E_{\text {pit }}-E_{\text {corr }}$ were obtained. The value of $j_{\text {pass }(+200 \mathrm{mV})}=32 \mathrm{nA} \mathrm{cm}^{-2}$ was obtained in the heat affected zone formed in the shielding gas with 2.50 vol. $\%$ nitrogen. Accordingly, the pitting corrosion resistance of heat affected zone is considerably higher (Table 4). Fig. 11 shows the dependence of the passivation current density, $j_{\text {pass }}(+200 \mathrm{mV})$, and the potential of metastable pit formation, $E_{\text {mpit }}$, for the heat affected zone (HAZ).

The chromium depletion of the grain boundary areas does not depend on the nitrogen amount. Nitrogen that reaches the heat affected zone by diffusion increases the passive layer stability, which probably makes the nucleation of pits more difficult. Therefore, the beneficial effect of nitrogen may be explained by an increase of nitrogen concentration under the passive film, as it was noticed by JargeliusPettersson (1999).

\subsubsection{Intergranular corrosion resistance}

Intergranular corrosion was tested in the base metal, in the welded joint formed in the nitrogen-free shielding gas, as well as in the shielding gas with nitrogen. The results obtained are shown in Fig. 12. The value of the reactivation charge $Q_{r}$ is the lowest in the base metal. A higher $Q_{r}$ value was obtained in the heat affected zone (HAZ) formed in the shielding gas with or without nitrogen. Accordingly, the nitrogen amount in the shielding gas has no significant influence on the $Q_{r}$ values (Fig. 13).

The quantitative data for the base meal and the heat affected zone (HAZ) obtained from the experimental curves in Fig. 12 are given in Table 6.

The indicators of the susceptibility to intergranular corrosion $\left(Q_{\mathrm{r}}\right)$ $\left.Q_{\mathrm{p}}\right)_{\mathrm{GBA}}$ (calculated using Eq. (2)) are also shown in Table 6. A very low value of $\left(Q_{\mathrm{r}} / Q_{\mathrm{p}}\right)_{\mathrm{GBA}}$ for the base metal indicates that stainless steel is not susceptible to intergranular corrosion. A higher value of $\left(Q_{r} / Q_{p}\right)_{\mathrm{GBA}}$ indicates that the heat affected zone is slightly sensitised, regardless of the nitrogen amount in the shielding gas (Table 6). The amount of nitrogen that reached the heat affected zone probably did not have a significant influence on the kinetics of chromium nitride precipitation, i.e. on the change in the resistance to intergranular corrosion.

Based on the results in Fig. 12 and in Table 6, it can be concluded 
that the base metal is resistant to intergranular corrosion, while the heat affected zone (HAZ) is slightly sensitised. The dependence between $\left(Q_{\mathrm{r}} / Q_{\mathrm{p}}\right)_{\mathrm{GBA}}$ and the amount of nitrogen in the shielding gas is given in Fig. 13.

The SEM micrographs of the stainless steel surface after the intergranular corrosion testing are shown in Fig. 14.

A slight dissolution of the grain boundary areas in the heat affected zone occurred in the chromium-depleted regions (Fig. 14b) due to precipitation of chromium rich carbides along the grain boundaries. In general, a stainless steel type susceptible to intergranular corrosion is also susceptible to stress corrosion cracking; therefore, the DL EPR method can be used to estimate the susceptibility of a stainless steel to stress corrosion cracking, as suggested in ISO 12732 standard (2006).

Although the tested stainless steel contains a relatively small amount of carbon ( 0.04 mass.\% C), a mild sensitisation in the heat affected zone occurred during welding. The level of sensitisation in the heat affected zone is below the level at which intergranular corrosion can occur under operating conditions. However, at this level of sensitisation, the pitting corrosion resistance of the stainless steel was reduced. If the value of the indicator $Q_{\mathrm{r}} / Q_{\mathrm{p}}>5 \%$, it can be expected that intergranular corrosion will occur under operating conditions, in accordance with ISO 12732 standard (2006).

\subsubsection{Welding current effect}

Fig. 15 shows the welding current influence on pitting corrosion resistance and susceptibility to intergranular corrosion both in the base metal and the heat affected zone (HAZ).

Susceptibility to intergranular corrosion in the heat affected zone increases at higher welding current levels (Fig. 15). This can be explained by significant depletion in chromium of the grain boundary areas due to increased heat input at higher welding current values. Pitting corrosion resistance in the heat affected zone is reduced when welding current is increased, as indicated by the values of $E_{\mathrm{mpit}}, E_{\mathrm{pit}}$, and $E_{\text {pit }}-E_{\text {corr }}$ (Table 7). The summary results of the influence of the welding current level to resistance to pitting corrosion and intergranular corrosion are given in Table 7 .

This can also be explained by depletion in chromium of the grain boundary areas at higher heat inputs. In accordance with the observations of Ryan et al. (2002), it can be assumed that, with a heat input increase, the chromium-rich phases precipitate on the boundaries of MnS inclusions. As a result, there is significant depletion in chromium in the regions close to MnS inclusions, which facilitates the formation of pits. Jegdić et al. (2017) considered in detail the influence of the welding current level on pitting corrosion resistance and susceptibility to intergranular corrosion in welded joints of $\mathrm{X} 5 \mathrm{CrNi18}-10$ stainless steel.

\section{Conclusions}

- Pitting corrosion resistance of the X5CrNi18-10 stainless steel welded joints formed with nitrogen in the shielding gas is higher than in the welded joints formed without nitrogen in the shielding gas for approximately $30 \%-40 \%$.

- The nitrogen content in the shielding gas did not affect the resistance of the welded joints to intergranular corrosion.

- The passivation current density is shown to be a good indicator of pitting corrosion resistance of welded joints.

- In the welded joints formed without nitrogen in the shielding gas, the resistance to pitting corrosion in the heat affected zone is about $30 \%$ lower than in the base metal. The pitting corrosion resistance values of the weld metal and the base metal are similar.

- Increase of the welding current level has led to the lower pitting corrosion resistance and integranular corrosion resistance of the welded joints for approximately $40 \%$ and three times, respectively.

- Hardness values of the weld metal and the heat affected zone are slightly lower than the base metal hardness value.

\section{Acknowledgement}

The Ministry of Education, Science and Technological Development of the Republic of Serbia has supported this work financially through TR 34028 and TR 35021 Projects.

\section{References}

Bayoumi, F.M., Ghanem, W.A., 2005. Effect of nitrogen on the corrosion behavior of austenitic stainless steel in chloride solutions. Mater. Lett. 59, 3311-3314.

Davis, J.R., 2006. Corrosion of Weldments. ASM International, Materials Park, Ohio, pp. 43-75.

Galvele, J.R., 1976. Transport processes and the mechanism of pitting of metals. J. Electrochem. Soc. 123, 464-474.

Grubb, J.F., 2011. Austenitic and feritic stainless steels. In: Revie, R.W. (Ed.), Uhlig's Corrosion Handbook, third edition. John Wiley \& Sons, New Jersey, pp. 657-693.

Ida, N., Muto, I., Sugawara, Yu, Hara, N., 2017. Local electrochemistry and in situ microscopy of pitting at sensitized grain boundary of type 304 stainless steel in $\mathrm{NaCl}$ solution. J. Electrochem. Soc. 164, C779-C787.

Jargelius-Pettersson, R.F.A., 1999. Electrochemical investigation of the influence of nitrogen alloying on pitting corrosion of austenitic stainless steels. Corros. Sci. 41 1639-1664.

Jegdić, B., Bobić, B., Nedeljković, D., Alić, B., 2017. Influence of welding current intensity on pitting corrosion resistance in welded joint of stainless steel X5CrNi18-10. Zasch. Mater. 58, 297-303.

Jegdić, B., Dražić, D.M., Popić, J.P., 2008. Open circuit potentials of metallic chromium and 304 stainlass steel in aqueus sulphuric acid solution and the influence of chloride ions on them. Corros. Sci. 50, 1235-1244.

Kaneko, K., Fukunaga, T., Yamada, K., Nakada, N., Kikuchi, M., Saghi, Z., Barnard, J.S., Midgley, P.A., 2011. Formation of M23C6-type precipitates and chromium-depleted zones in austenite stainless steel. Scr. Mater. 65, 509-512.

Ke, R., Alkire, R., 1995. Initiation of corrosion pits at inclusions on 304 stainless steel. J. Electrochem. Soc. 142, 4056-4062.

Kim, Y.S., 2010. Synergistic effect of nitrogen and molybdenum on localized corrosion of stainless steels. Corros. Sci. Technol. 9, 20-28.

Lai, R., Cai, Y., Wu, Y., Li, F., Hua, X., 2016. Influence of absorbed nitrogen on microstructure and corrosion resistance of 2205 duplex stainless steel joint processed by fiber laser welding. J. Mater. Proc. Technol. 231, 397-405.

Lo, K.H., Shek, C.H., Lai, J.K.L., 2009. Recent developments in stainless steels. Mater. Sci. Eng. R 65, 39-104.

Osozawa, K., Okato, N., Fukase, Y., Yokota, K., 1975. Effects of alloying elements on the pitting corrosion of stainless steel, (B. Gijyutsu). Corros. Eng. 24, 1-7.

Raja, V.S., Varshney, S.K., Raman, R., Kulkarni, S.D., 1998. Influence of nitrogen on the pitting corrosion behavior of 904L weld clad. Corros. Sci. 40, 1609-1625.

Ryan, M.P., Williams, D.E., Chater, R.J., Hutton, B.M., McPhail, D.S., 2002. Why stainless steel corrodes. Nature 415, 770-774.

Seys, A.A., Brabers, M.J., Van Haute, A.A., 1974. Analysis of the influence of hydrogen on pitting corrosion and stress corrosion of austenitic stainless steel in chloride environment. Corrosion 30, 47-52.

Tang, Y., Zuo, Y., Wang, J., Zhao, X., Niu, B., Lin, B., 2014. The metastable pitting potential and its relation to the pitting potential for four materials in chloride solutions. Corros. Sci. 80, 111-119.

Tian, W., Du, N., Li, S., Chen, S., Wu, Q., 2014. Metastable pitting corrosion of 304 stainless steel in 3.5\% NaCl solution. Corros. Sci. 85, 372-379.

Yanliang, H., Kinsella, B., Becker, T., 2008. Sensitisation identification of stainless steel to intergranular stress corrosion cracking by atomic force microscopy. Mater. Lett. 62, 1863-1866.

Zhang, Z., Jing, H., Xu, L., Han, Y., Zhao, L., Zhou, C., 2017. Effects of nitrogen in shielding gas on microstructure evolution and localized corrosion behavior of duplex stainless steel welding joint. Appl. Surf. Sci. 404, 110-128. 